\title{
Editorial: Linking Hydrological and Biogeochemical Processes in Riparian Corridors
}

\author{
Dipankar Dwivedi ${ }^{1 *}$, Sarah E. Godsey ${ }^{2}$ and Timothy D. Scheibe ${ }^{3}$ \\ ${ }^{1}$ Lawrence Berkeley National Laboratory, Berkeley, CA, United States, ${ }^{2}$ Department of Geosciences, Idaho State University, \\ Pocatello, ID, United States, ${ }^{3}$ Pacific Northwest National Laboratory, Richland, WA, United States
}

Keywords: riparian corridors, hydrobiogeochemical process, hydrologic connectivity, hydrologic exchange flows, C-Q hysteresis loops

\section{Editorial on the Research Topic}

\section{Linking Hydrological and Biogeochemical Processes in Riparian Corridors}

The riparian corridor is a key component of the critical zone and an essential component of watershed systems. According to Merriam-Webster Dictionary, the word riparian is derived from the Latin word riparius, meaning "existing alongside a river." Riparian corridors typically extend from a few meters to hundreds of meters adjacent to a river and are marked by rich biodiversity, vegetation, and intense biogeochemical activity. They act as integrators of watershed processes and constitute the primary pathways for the subsurface geochemical exports from the watershed. Although riparian corridors comprise only $2-10 \%$ of a watershed's area, as much as $90-98 \%$ of biogeochemical processing in watersheds occurs in this region, thereby affecting the subsurface geochemical exports and downstream river water quality. Indeed, the riparian corridor is a good example of the Pareto principle (e.g., Dwivedi et al., 2018a; McClain et al., 2003; Bernhardt et al., 2017). This outsized contribution occurs at the interface between aquatic (river) and terrestrial (land) environments, where interactions between hydrologic and biogeochemical processes are intensified. Variations in the river corridor over time can thus also have outsize impacts. Therefore, it is important to understand the hydrological and biogeochemical linkages in riparian corridors to determine water availability and quality for sustainable management.

Riparian corridors include various subsystems, such as hyporheic zones, meanders, wetlands, and lagoons, all of which impact river water quality (Figure 1). These subsystems demonstrate distinct biogeochemical potential depending upon their hydrologic connectivity to the main channel. However, several hurdles must be overcome to improve the predictive capability of riparian corridor processes across scales. This Research Topic aimed to enhance our understanding and predictive capability related to linked hydrological and biogeochemical processes in riparian corridors. We received contributions across a wide spectrum of topics, including hydrologic exchange and river connectivity as well as geochemical exports of carbon, nitrogen, colloids, and microbial dynamics (Figure 2). These topics also involved novel method development, new observational networks, advanced mechanistic modeling, and the use of artificial intelligence and machine learning approaches. Below, we briefly synthesize these contributions under two groups focused on dynamic hydrologic connectivity and microbial and physical controls on spatial patterns in river corridors. 


\section{Floodplain/Meanders}

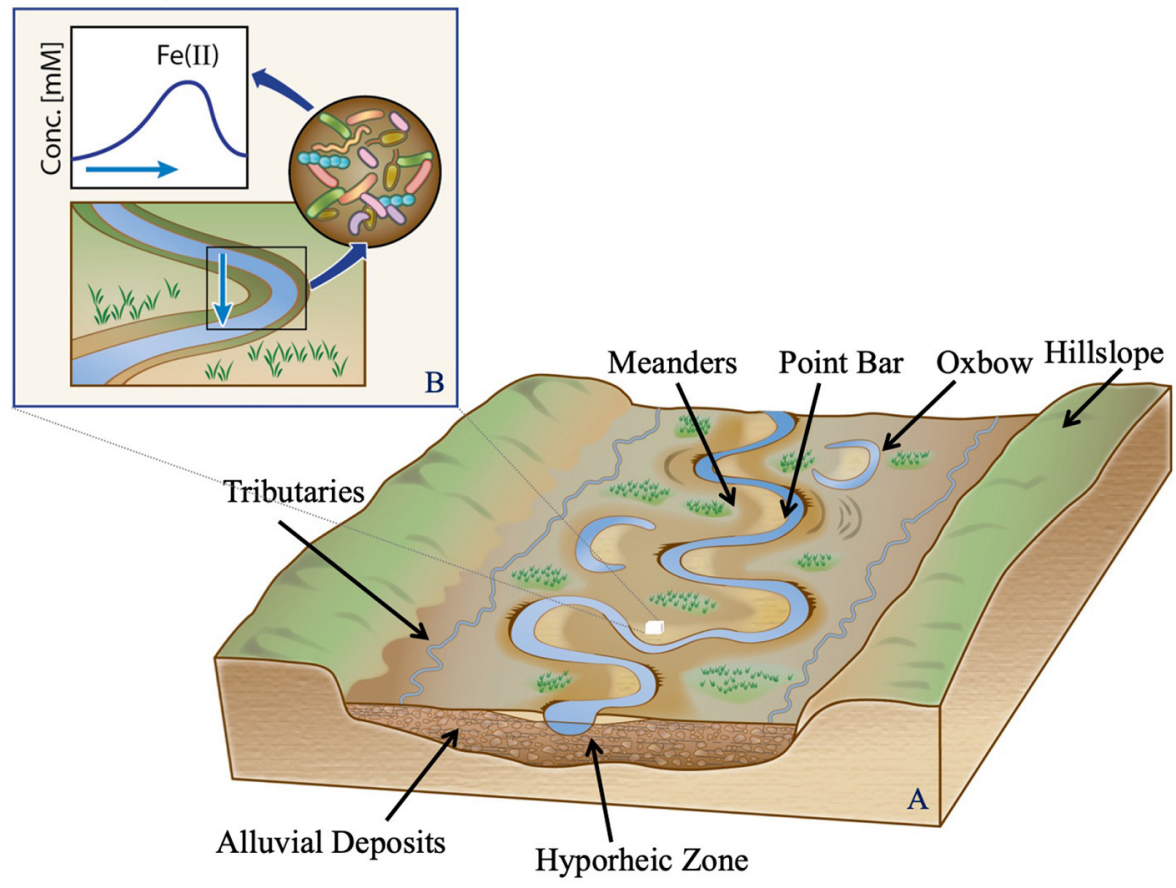

FIGURE 1 | (A) The riparian corridors include various subsystems, such as hyporheic zones, meanders, wetlands, and lagoons, all of which impact river water quality (modified from Natural levees, Pearson Prentice Hall, Inc.). (B) A zoomed-in view highlights the importance of temporal dynamics within an intrameander region.

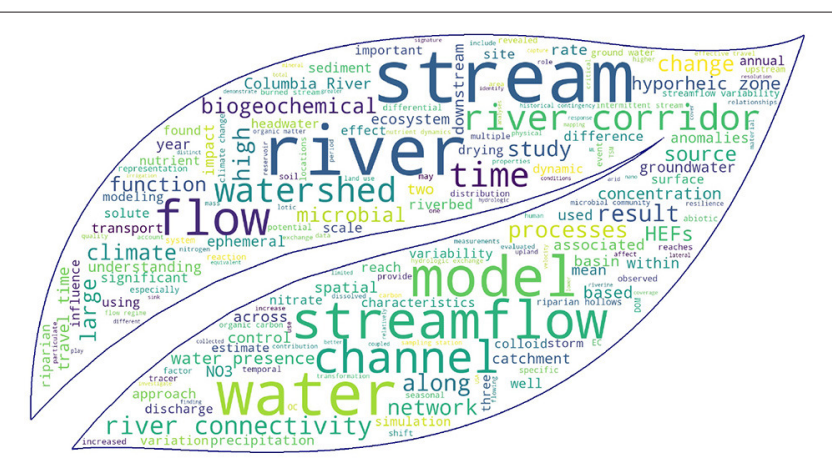

FIGURE 2 | Linking hydrological and biogeochemical processes in riparian corridors include a wide spectrum of topics, such as hydrologic exchange and river connectivity, geochemical exports, and microbial dynamics addressing critical gaps in our understanding of changes in river corridors over different spatial and temporal scales.

\section{DYNAMIC HYDROLOGIC CONNECTIVITY}

Hydrologic connectivity is a primary factor leading to high biogeochemical activity in riparian corridors. River water and its chemical and biological constituents are critical to the growth and metabolic function of plants, microbes, and other organisms.

One important aspect of hydrologic connectivity relates to intermittent and ephemeral streams, which exhibit disconnected surface flows during drought periods as sections of a river network dry up. Based on a statistical analysis of gauge data and a reduced-complexity heuristic model parameterized using data readily available in unstudied catchments, Ward et al. quantified the impacts of climate change on river channel connectivity in a mountainous fifth-order river basin in the United States (U.S.) Pacific Northwest. They found that not only are headwater streamflows generally decreasing, especially during low-flow periods, but river connectivity is also being reduced through decreases in flow permanence. They noted that increasing flow impermanence under climate change affects connectivity and associated biogeochemical functions as well as regulatory protections that may be afforded only to permanent streams. Temporal patterns of surface water and soil moisture, along with the related hydrologic connectivity, also vary across spatial gradients in climate, but there may be limits to past categorization of streamflow patterns as "perennial" and "nonperennial” (Busch et al., 2020). Gallo et al. combined electrical resistivity sensors with available stream gauge data to identify five distinct flow regimes in southern Arizona streams: (1) dry ephemeral, (2) wet ephemeral, (3) dry intermittent, (4) wet intermittent, and (5) seasonally intermittent. This new classification approach was based not only on streamflow, but also on water presence in ponds or soils, which may be needed to better predict ecological function in dryland systems. Nutrient cycling is one such function of riparian ecosystems; Lohse et al. investigated the impact of climate change and fluctuating streamflow regimes on litter decomposition and subsequent 
nutrient dynamics in ephemeral and intermittent streams. They found that climatic conditions do not affect litter decay rates in upland and riparian positions and that flow duration is a better indicator of ephemeral and intermittent stream function than streamflow alone. MacNeille et al. considered the compounding effects of wildfire and stream drying in intermittent stream networks. In spatiotemporal studies of two catchments that experienced partial drying of the stream networks, one of which had been burned, they observed similar temporal patterns in hydrologic and biogeochemical processes, with the primary difference being a sharp decrease in total nitrogen in the burned catchment streams during the drying period.

On the other end of the spectrum from drying streams is the role of lentic (ponded) water bodies in expanding the riparian corridor. Harvey and Schmadel used a new high-resolution conterminous U.S. (CONUS)-wide dataset to investigate the relative contribution of lotic (flowing) and lentic (ponded) waters to river networks at continental scales. They found that the character of river corridors has varied widely over four centuries of human disturbance, including reservoir construction and beaver extirpation, which have led to a two to four times increase in water residence times in the 20th century, which in turn can affect water quality. Konrad et al. demonstrated that it is also necessary to account for the temporal variability of streamflow when estimating residence or travel times through the stream network. They developed a statistical approach to quantify flowpath travel times to steams and inferred that streamflow variability is the main control of regional- to continental-scale variation in stream travel times.

One key reason that accounting for streamflow variability is important is hydrologic exchange flows (HEFs), which are the dynamic two-way exchanges of water between the flowing river channel and subsurface and other relatively slow-moving environments. HEFs affect residence times and biogeochemical reactions that control how nutrients, including carbon and nitrogen, are retained, released, and transformed within the riparian corridor. HEFs vary significantly in space and time depending on several factors, such as river-stage, riverbed morphology, and hydraulic conductivity. However, measurements of HEFs at the watershed scale are nontrivial; they can be indirectly measured using high-frequency temperature and electrical conductivity along the bed of the river (Conner et al.). Alternatively, high-resolution, three-dimensional reactive transport models can be advantageous for accurately quantifying $\mathrm{HEFs}$ but require detailed parameterization of spatially heterogeneous properties. Although sediment grainsize distribution can be used as a proxy to derive the spatial distribution of hydraulic properties, sediment grainsize measurements are typically spatially sparse. Ren et al. developed a novel method using machine learning (ML) to categorize and map the spatial distributions of riverbed substrate grain size in the Hanford Reach located in the Columbia River Basin. Representing the effects of spatial heterogeneity of physical properties along a river enables high-resolution numerical models to appropriately capture residence times and HEFs. However, such models may currently be computationally prohibitive over large spatial domains. Fang et al. compared a surrogate model (transient storage model) with high-resolution simulations of reactive transport in a 20-kilometer reach of the mainstem Columbia River and identified strengths and weaknesses of the surrogate approach.

Painter studied two alternative representations of HEFs and solute transport: (1) a stochastic Lagrangian travel time model of advective pumping and (2) a multirate diffusive exchange model. Although both representations produced comparable results for conservative tracers, they predicted significantly different results for reactive species. The multirate diffusive exchange model assumes that each transient storage zone is connected with the channel and well-mixed. Consequently, transient storage zones do not undergo anoxic conditions and fail to represent redox zonation adequately. The advective pumping model representing only one-dimensional flowpaths through the hyporheic zone is not suitable for complex geometries. Painter suggested combining diffusion- and advection-based conceptualization to accurately capture multiscale reactive transport in river corridors.

\section{HYDROLOGICAL AND MICROBIAL CONTROLS ON SPATIAL PATTERNS IN RIVER CORRIDORS}

Efforts to understand riparian connectivity and associated ecological function, such as those described above, are aimed at significantly advancing the predictive understanding of geochemical exports at watershed and basin scales. These depend strongly on the biogeochemical processes that are tightly related to hydrologic connectivity. For example, Bicknell et al. demonstrated that hydrologic connectivity-in this case, between a stream and its tributaries along with man-made delivery and drain canals-could be exploited to mitigate nutrient loads. Different connected channels seasonally act as either nutrient sources or sinks, so they can be managed to meet societal needs and reduce nutrient loads. Both connected channels and microtopographic features, such as riparian hollows, located along the sides of a river, can act as a source or sink of reactive chemical species and have an outsized impact on river chemistry. Working in the mountainous headwater East River Colorado watershed, Rogers et al. explored the effects of riparian hollows as $\mathrm{N}$-cycling hotspots and as critical small-scale controls on watershed-scale trends. Indeed they found that groundwater upwelling limits $\mathrm{N}$ transformations which suggests that even though riparian hollows are key nitrate sources, they are also the main inhibitors of nitrate delivery at the watershed scale. For the same watershed, Arora et al. developed a differential C$\mathrm{Q}$ approach to characterize spatial variability in solute behavior across stations, as well as investigate their controls, by following a different spatial scheme and organizing the river into multiple sections. Using water quality data collected over four water years (2015-2018) in the East River in Colorado, they compared traditional and differential C-Q relationships in predicting solute behavior among three sampling stations distributed throughout the river. The new differential C-Q approach performed just as well as the traditional approach but allowed for source 
apportionment and the identification of critical stream segments that assimilate chemicals like nitrate and phosphate.

Source apportionment, which is important for advancing the predictive understanding of geochemical exports across the spatial scale, is a complex mechanism comprising several factors. For instance, biotic (e.g., microbial dynamics) and abiotic (e.g., mineral association, sunlight) processes exert significant controls on solute transport and transformation within multiple reaches in a river corridor. Furthermore, storm and peak discharge events introduce notable spatio-temporal variability in solute concentrations. Using storm-induced variations of biomarkers at three sampling stations, Kim et al. characterized particulate organic carbon sources in Clear Creek in Iowa. They found that fatty acid-rich organic matter mobilizes algal mats in the stream channel at the storm's early stage when water velocities begin to increase and that understanding complex, storm-driven transport requires high-resolution tracer information in both space and time. Rod et al. compared the coupled relationships between soil organic matter and minerals using batch and column leaching experiments under aerobic and anaerobic conditions and applying multiple imaging and analytical techniques. Using two riparian sedimentsnamely, Columbia River in Washington and Tims Branch in South Carolina-they characterized natural organic carbon fraction associated with mineral nano-colloids (1-100nm), small colloids $(<450 \mathrm{~nm})$, and other particles $(<1,000 \mathrm{~nm})$ and found that the dispersible colloids facilitate the release of organic carbon.

Although organic carbon drives redox processes in the riparian corridors, accounting for the biotic and abiotic chemical transformation of organic matter is equally important to enhance predictive understanding of watershed processes. For example, Fudyma et al. characterized organic matter in the hyporheic zone of the Columbia River using high-resolution Fourier-transform ion cyclotron resonance mass spectrometry. They inferred that the abiotic degradation of organic matter, potentially driven by sunlight, can increase dissolved organic matter's availability to the hyporheic zone, which should be represented in predictive models to account for microbial activity adequately and enhance understanding of watershed dynamics. Furthermore, they concluded that the hyporheic zone is metabolically active irrespective of the river-stage. However, riverine microbial communities are shaped by the local environment, including climate, geomorphology, land cover, and anthropogenic activities in a watershed, and can help monitor relevant upstream characteristics. Song et al. linked the history of river-stage or groundwater fluctuations (or historical contingency) with the shifts in microbial community and, thereby, with specific microbial activity. They further demonstrated that the historical contingency was more pronounced for specialized functions associated with individual species than the community functions (i.e., functional redundancy) where one species could substitute for another. URycki et al. exploited knowledge of the evolution of riverine microbial communities and their relationship with upstream macroscale conditions and hydrology. They assessed the correlation between microbial community composition and 40 basin characteristics reflecting the geomorphology, climate, land cover, and level of human development in stream catchments. They found differing degrees of correlation with basin size, suggesting opportunities still remain to better understand the heterogeneity of river corridor microbial communities and their impact on water quality.

\section{CONCLUDING REMARKS}

Over the past several decades, the complexity of rivers and their adjacent environments and the important roles that they play in watershed function have been increasingly recognized (Harvey and Gooseff, 2015; Chen et al., 2020; Dwivedi et al., $2018 b)$. The large number of contributions to this Research Topic reflect continued high interest in understanding and quantifying the interactions between hydrological, microbial, and biogeochemical processes that underlie ecological health and water quality in these critical systems across spatiotemporal scales. It is particularly encouraging to see that hydrological connectivity has received considerable attention in this Research Topic to unravel the conundrum of high biogeochemical activity in riparian corridors. However, it is important to realize that there is no consensus about the definition of hydrological connectivity across fields (e.g., Wohl et al., 2019; Bracken et al., 2015; Wainwright et al., 2011; Singh and Sinha, 2019). Further, we need to acknowledge the wide range of complexity of dynamic hydrological connectivity appropriately to enhance process understanding of riparian corridors. Finally, we expect that emerging technologies, radical collaboration, new constructs, and open science principles (e.g., Hubbard et al., 2020; Arora et al., 2019) will keep transforming predictive capabilities of hydrobiogeochemical behavior of riparian corridors.

\section{AUTHOR CONTRIBUTIONS}

All authors listed have made a substantial, direct and intellectual contribution to the work, and approved it for publication.

\section{FUNDING}

DD was supported in part by the Watershed Function Science Focus Area and ExaSheds projects at Lawrence Berkeley National Laboratory funded by the U.S. Department of Energy, Office of Science, and Biological and Environmental Research under Contract No. DE-AC02-05CH11231. SG was supported in part by NSF EAR 1653998 and RC CZO Coop Agreement EAR 1331872. TS was supported by the River Corridor Science Focus Area project at Pacific Northwest National Laboratory funded by the U.S. Department of Energy, Office of Biological and Environmental Research, and Environmental System Science program.

\section{ACKNOWLEDGMENTS}

We thank Diana Swantek of Berkeley Lab for assistance with preparing Figure 1. 


\section{REFERENCES}

Arora, B., Dwivedi, D., Faybishenko, B., Jana, R. B., and Wainwright, H. M. (2019). Understanding and predicting vadose zone processes. Rev. Mineral. Geochem. 85, 303-328. doi: 10.2138/mg.2019.85.10

Bernhardt, E. S., Blaszczak, J. R., Ficken, C. D., Fork, M. L., Kaiser, K. E., and Seybold, E. C. (2017). Control points in ecosystems: moving beyond the hot spot hot moment concept. Ecosystems 20, 665-682. doi: 10.1007/s10021-016-0103-y

Bracken, L. J., Turnbull, L., Wainwright, J., and Bogaart, P. (2015). Sediment connectivity: a framework for understanding sediment transfer at multiple scales. Earth Surf. Process. Landf. 40, 177-188. doi: 10.1002/esp.3635

Busch, M. H., Costigan, K. H., Fritz, K. M., Datry, T., Krabbenhoft, C. A., Hammond, J. C., et al. (2020). What's in a name? Patterns, trends, and suggestions for defining non-perennial rivers and streams. Water 12:1980. doi: $10.3390 / w 12071980$

Chen, X., Lee, R. M., Dwivedi, D., Son, K., Fang, Y., Zhang, X., et al. (2020). Integrating field observations and process-based modeling to predict watershed water quality under environmental perturbations. J. Hydrol. 125762. doi: 10.1016/j.jhydrol.2020.125762

Dwivedi, D., Arora, B., Steefel, C. I., Dafflon, B., and Versteeg, R. (2018a). Hot spots and hot moments of nitrogen in a riparian corridor. Water Resour. Res. 54, 205-222. doi: 10.1002/2017WR022346

Dwivedi, D., Steefel, C. I., Arora, B., Newcomer, M., Moulton, J. D., Dafflon, B., et al. (2018b). Geochemical exports to river from the intrameander hyporheic zone under transient hydrologic conditions: East River Mountainous Watershed, Colorado. Water Resour. Res. 54, 8456-8477. doi: 10.1029/2018WR023377

Harvey, J., and Gooseff, M. (2015). River corridor science: hydrologic exchange and ecological consequences from bedforms to basins. Water Resour. Res. 51, 6893-6922. doi: 10.1002/2015WR017617
Hubbard, S. S., Varadharajan, C., Wu, Y., Wainwright, H., and Dwivedi, D. (2020). Emerging technologies and radical collaboration to advance predictive understanding of watershed hydrobiogeochemistry. Hydrol. Process. 34, 3175-3182. doi: 10.1002/hyp.13807

McClain, M. E., Boyer, E. W., Dent, C. L., Gergel, S. E., Grimm, N. B., Groffman, P. M., et al. (2003). Biogeochemical hot spots and hot moments at the interface of terrestrial and aquatic ecosystems. Ecosystems 6, 301-312. doi: 10.1007/s10021-003-0161-9

Singh, M., and Sinha, R. (2019). Evaluating dynamic hydrological connectivity of a floodplain wetland in north Bihar, India using geostatistical methods. Sci. Total Environ. 651, 2473-2488. doi: 10.1016/j.scitotenv.2018. 10.139

Wainwright, J., Turnbull, L., Ibrahim, T. G., Lexartza-Artza, I., Thornton, S. F., and Brazier, R. E. (2011). Linking environmental regimes, space and time: Interpretations of structural and functional connectivity. Geomorphology 126, 387-404. doi: 10.1016/j.geomorph.2010.07.027

Wohl, E., Brierley, G., Cadol, D., Coulthard, T. J., Covino, T., Fryirs, K. A., et al. (2019). Connectivity as an emergent property of geomorphic systems. Earth Surf. Process. Landf. 44, 4-26. doi: 10.1002/esp.4434

Conflict of Interest: The authors declare that the research was conducted in the absence of any commercial or financial relationships that could be construed as a potential conflict of interest.

Copyright (C) 2021 Dwivedi, Godsey and Scheibe. This is an open-access article distributed under the terms of the Creative Commons Attribution License (CC BY). The use, distribution or reproduction in other forums is permitted, provided the original author(s) and the copyright owner(s) are credited and that the original publication in this journal is cited, in accordance with accepted academic practice. No use, distribution or reproduction is permitted which does not comply with these terms. 